\title{
Piper betle leaf extract affects the quorum sensing and hence virulence of Pseudomonas aeruginosa PAO1
}

\author{
Siraj Datta ${ }^{1}$ Debanjan Jana ${ }^{1}$ Tilak Raj Maity ${ }^{1} \cdot$ Aveek Samanta $^{1}$. \\ Rajarshi Banerjee ${ }^{1}$
}

Received: 2 June 2015 / Accepted: 3 August 2015 / Published online: 9 January 2016

(c) The Author(s) 2016. This article is published with open access at Springerlink.com

\begin{abstract}
Quorum sensing (QS) plays an important role in virulence of Pseudomonas aeruginosa, blocking of QS ability are viewed as viable antimicrobial chemotherapy and which may prove to be a safe anti-virulent drug. Bioactive components from Piper betle have been reported to possess antimicrobial ability. This study envisages on the anti-QS properties of ethanolic extract of $P$. betle leaf (PbLE) using $P$. aeruginosa PAO1 as a model organism. A marked reduction in swarming, swimming, and twitching ability of the bacteria is demonstrated in presence of PbLE. The biofilm and pyocyanin production also shows a marked reduction in presence of PbLE, though it does not affect the bacterial growth. Thus, the studies hint on the possible effect of the bioactive components of PbLE on reducing the virulent ability of the bacteria; identification of bioactive compounds should be investigated further.
\end{abstract}

Keywords Anti Quorum Sensing properties - Piper betle leaf extract $\cdot$ Pseudomonas aeruginosa $\cdot$ Biofilm production $\cdot$ Pyocyanin assay $\cdot$ Mobility pattern

Electronic supplementary material The online version of this article (doi:10.1007/s13205-015-0348-8) contains supplementary material, which is available to authorized users.

Siraj Datta

dattasiraj@gmail.com

1 Department of Biotechnology, Haldia Institute of Technology, Haldia, West Bengal 721657, India

\section{Introduction}

Amongst proteobacteria, a widespread cell-to-cell communication (quorum sensing; QS) phenomenon is observed (Krishnan et al. 2012). QS is used to regulate the diverse bacterial function amongst which bioluminescence, biofilm formation, virulence, pigment production, motility and polysaccharide production have been widely studied (Fuqua and Greenberg 2002; Whitehead et al. 2001). Pseudomonas aeruginosa (belonging to Gamma Proteobacteria) is a prevalent opportunistic human pathogen and primarily infecting immune compromised patients (Govan and Deretic 1996). It causes serious eye (Zhu et al. 2004), ear (Tron et al. 2004), burn wounds (Friedstat et al. 2013), urinary tract (Packiavathy et al. 2014) and respiratory tract infection (cystic fibrosis) (Smith et al. 2013; Lyczak et al. 2002). Available antibiotic therapy does not respond to these infections; especially predisposed to infection with $P$. aeruginosa and hence the bacterium is developing new resistance, responsible for high rates of morbidity and mortality (Lanini et al. 2011). Alternative strategies to conventional antibiotic therapy are therefore required.

QS helps the bacteria to detect their population density by producing, releasing and perceiving the small autoinducer molecules and coordinate a common action such as releasing the virulence factors (Girard and Bloemberg 2008; Jimenez et al. 2012; Kumar et al. 2015). Thus, the virulence phenotypes of the bacteria can be quenched by blocking the QS. QS inhibitor (QSI) may inhibit the QS mechanism and be able to attenuate the virulence of the pathogen and are helpful to break the antibiotic resistance (Vattem et al. 2007; Adonizio et al. 2008). Recent studies have been demonstrated that QSI compound(s) can be found in higher plants such as vanilla (Choo et al. 2006),

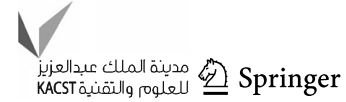


raspberry (Vattem et al. 2007), clove (Krishnann et al. 2012). In light of these findings, we look into Ayurveda, the oldest traditional medicine system of India, which reports large number of herbs possessing potential preventive and curative properties (Mukherjee and Wahile 2006). In Ayurveda, the use of betel leaves (Piper betle L.) in various ways, as carminative, stimulant, antiseptic, antifungal, antibacterial, anti-diabetic and anti-allergic agent have been mentioned (Guha 2006). The extract of betel leaves have been reported to possess many biological activities that are able to control the growth of many Gram positive and Gram negative microbes (Nair and Chanda 2008). No information however is available on betel leaf extracts to demonstrate its anti-QS activity.

In this study, we report of the anti-QS properties of ethanolic extract $P$. betle leaf (PbLE); effects of the mobility patterns (namely Swarming, Swimming and Twitching), reduction on biofilm and pyocyanin production in presence of different concentrations of PbLE. This in turn reflects on the virulence of model microorganism $P$. aeruginosa PAO1.

\section{Materials and methods}

\section{Bacterial strains and subculture conditions}

Pseudomonas aeruginosa PAO1 (MTCC-3541) was obtained from microbial type culture collection and Gene Bank, Chandigarh, India. The stock culture of the test organism was maintained in medium containing $30 \%$ glycerol in cryogenic vials were kept at $-70{ }^{\circ} \mathrm{C}$. Working cultures were kept at $4{ }^{\circ} \mathrm{C}$ on nutrient agar slants and were periodically transferred to fresh slants. A loop full of culture from the slants were transferred to nutrient broth and grown overnight at $37^{\circ} \mathrm{C}$. The overnight grown culture was used for the subsequent study.

\section{Preparation of ethanolic extract of betel leaves (PbLE)}

Freshly cut betel leaves (Piper betle L. ver. Kali Bangla; landrace of Paschim Medinipur, West Bengal, India) were dried in hot air oven $\left(40 \pm 1{ }^{\circ} \mathrm{C}\right)$ for $48 \mathrm{~h}$, crushed in mortar and pestle and the leaf powder were stored at $-20{ }^{\circ} \mathrm{C}$. Leaf powder was Soxhlet extracted using $80 \%$ ethanol for $20 \mathrm{~h}$. The crude extract was concentrated and dried in rotary vacuum evaporator below $50{ }^{\circ} \mathrm{C}, 100 \mathrm{mg}$ dried extract was dissolved in $500 \mu \mathrm{l}$ of dimethylsulfoxide (DMSO) and then diluted to $10 \mathrm{mg} / \mathrm{ml}$ working PbLE stock by adding triple distilled water (Maity et al. 2014).

\section{Mobility patterns assays}

\section{Swarming assay}

Tan et al. (2013) was followed with minor modifications for the preparation of the swarm plate assay of $P$. aeruginosa PAO1. Petri plates were prepared using $0.5 \mathrm{~g}$ bacto agar, $0.5 \mathrm{~g}$ peptone, $0.2 \mathrm{~g}$ yeast extract and $1.0 \mathrm{~g}$ glucose per $100 \mathrm{ml}$ of distilled water. A set containing 25, 50, 75, $100 \mu \mathrm{g} / \mathrm{ml}$ of PbLE was seeded with $5 \mathrm{ml}$ of media and poured immediately on a $10 \mathrm{ml}$ of pre-warmed agar plate as an overlay. Overnight culture of the $P$. aeruginosa PAO1 culture was inoculated at the centre of the agar surface and the plate was incubated for $24 \mathrm{~h}$ at $37^{\circ} \mathrm{C}$.

With minor modifications, swimming and twitching assay was done following Inoue et al. (2008).

\section{Swimming assay}

Like the swarming plate, swimming plate assay media contained $1 \%$ nutrient broth, glucose $0.5 \%$, agar $0.3 \%$. The agar media was air dried for 5-10 min and the bacterial cells were gently inoculated using a tooth pick at the centre of the agar surface. Then the plate was incubated at $37{ }^{\circ} \mathrm{C}$ for $24-48 \mathrm{~h}$.

\section{Twitching assay}

The media for twitching assay contained $1 \%$ tryptone, $0.5 \%$ yeast extract, $0.5 \% \mathrm{NaCl}, 1 \%$ agar. In twitching assay, bacterial cells were stabbed into the bottom of a petri dish containing the said agar medium using a toothpick and incubated at $37{ }^{\circ} \mathrm{C}$ for $20 \mathrm{~h}$. The movement of the colony on the interface between the agar medium and the petri dish was observed.

\section{Pyocyanin assay}

Pyocyanin was extracted from overnight grown $P$. aeruginosa PAO1 culture supernatant. $25 \mu \mathrm{g} / \mathrm{ml}$ up to $200 \mu \mathrm{g} / \mathrm{ml}(25,50,75,100,125,150,175$ and $200 \mu \mathrm{g} / \mathrm{ml})$ of $\mathrm{PbLE}$ were mixed with freshly prepared $P$. aeruginosa culture $\left(2 \mathrm{ml}, \mathrm{OD}_{600}=0.1\right)$ and incubated overnight at $37{ }^{\circ} \mathrm{C}$. After $24 \mathrm{~h}, 2 \mathrm{ml}$ of chloroform was added to the culture supernatant and mixed vigorously. The chloroform layer was mixed with $1 \mathrm{ml}$ of $\mathrm{HCl}(0.2 \mathrm{M})$. After centrifugation $\left(8000 \mathrm{rpm}\right.$ for $10 \mathrm{~min}$ at $28{ }^{\circ} \mathrm{C}$ ) the relative concentration of Pyocyanin was measured as OD of the $\mathrm{HCl}$ layer at $520 \mathrm{~nm}$ against $0.2 \mathrm{M} \mathrm{HCl}$ as blank (Chong et al. 2011). 


\section{Biofilm formation and quantification}

An overnight culture of $P$. aeruginosa PAO1 was diluted to 1:100 into fresh medium and $100 \mu \mathrm{l}$ was added to each well of microtiter plate and incubated for $28-30 \mathrm{~h}$ at $37{ }^{\circ} \mathrm{C}$. After incubation, cells were dumped out by turning the plate over and shaking out the liquid. The plates were submerged in small tub of water, and shake the water out. The process was repeated. $125 \mu \mathrm{l}$ of a $0.1 \%$ aqueous solution of a crystal violet was added and the plates are incubated at room temperature for 10-15 min. Plates were rinsed 3-4 times in water and blotted on a stack of paper towels by turning the plates upside down and dried for a few hours or overnight. To quantitate, $200 \mu \mathrm{l}$ of $30 \%$ acetic acid was added to each well. Incubated for 10-15 min and $125 \mu \mathrm{l}$ was transferred to a new, flat-bottomed microtiter dish. OD at $\mathrm{A}_{540}-\mathrm{A}_{600}$ was read on a plate reader (Siddiqui et al. 2012).

\section{Assessment of bacterial growth}

Actively growing culture of $P$. aeruginosa PAO1 $(1 \mathrm{ml}$, $\left.\mathrm{OD}_{600}=0.1\right)$ was incubated in Luria Broth with different concentrations of PbLE $(50,100,150 \mu \mathrm{g} / \mathrm{ml}) . \mathrm{OD}_{600} \mathrm{~nm}$ was observed at every $2 \mathrm{~h}$ interval for consecutively $40 \mathrm{~h}$ to evaluate the relative growth in different experimental conditions.

\section{Statistical analysis}

All the above experiments were carried out in triplicates. The data were statistically analysed by conducting student's $t$ test and ANOVA. Statistical analysis and the graphs were constructed using MS excel.

\section{Results and discussion}

\section{Mobility patterns: swarming, swimming and twitching}

The graph (Fig. 1a) shows that a concentration beyond $25 \mu \mathrm{g} / \mathrm{ml} \mathrm{PbLE}$ inhibits the swarming activity drastically. A PbLE concentration of $50 \mu \mathrm{g} / \mathrm{ml}$ was seen to be inhibitory for swarming activity of the bacteria wherein more than $50 \%$ inhibition was observed irrespective of the hours of incubation. The slope between 25 and $50 \mu \mathrm{g} / \mathrm{ml}$ ( $m=0.56)$ after $24 \mathrm{~h}$ while the slope at the same concentration after $48 \mathrm{~h}(m=-1.08)$ indicates significantly that the rate of inhibition drastically increases after $24 \mathrm{~h}$.

After $24 \mathrm{~h}$ of incubation at $25 \mu \mathrm{g} / \mathrm{ml}$ with respect to control a difference of $13 \mathrm{~mm}$ in the zone of inhibition are observed. At the same period of incubation at $50 \mu \mathrm{g} / \mathrm{ml}$ swimming activity of $P$. aeruginosa PAO1 in presence of PbLE (Fig. 1b) diminished with increase in concentration (at $24 \mathrm{~h}$ ) but after $48 \mathrm{~h}$ of exposure, the rate of inhibition is almost $7.40 \%$. Though, beyond $50 \mu \mathrm{g} / \mathrm{ml}$ the inhibition rate comes to a constant irrespective of the hours of incubation.

Twitching activity in presence of PbLE (Fig. 1c) was seen to be diminishing but is not much of significance when compared to the control; a mere $10.71 \%$ decrease is seen after $24 \mathrm{~h}$ of incubation at $25 \mu \mathrm{g} / \mathrm{ml}$. Thereafter the rate of decrease remains constant.

Form the above observations, it could be said that PbLE has a destructive effect on the QS mechanisms of $P$. aeruginosa PAO1. The above inhibition activities were compared simultaneously with certain antibiotics like Ciprofloxacin, Gentamicin. The antibiotic Ciprofloxacin inhibited the growth of $P$. aeruginosa PAO1 but was found to be resistant to the antibiotic Gentamicin (Data not shown). Of all three QS motility mechanisms observed it has the most devastating effect on swarming activity which correlates with the findings of Tan et al. (2013).

\section{Biofilm and pyocyanin assay; inhibition biology of biofilm formation and resistance}

In our studies, a reduction is observed in biofilm production (Fig. 2) at concentrations beyond $50 \mu \mathrm{g} / \mathrm{ml}$. When compared to control sets the inhibition percentage could be said as $50 \mu \mathrm{g} / \mathrm{ml}(7.81 \%), 100 \mu \mathrm{g} / \mathrm{ml}(32.54 \%), 150 \mu \mathrm{g} / \mathrm{ml}$ (66.16\%), $200 \mu \mathrm{g} / \mathrm{ml}(75.35 \%)$ i.e. almost approximately fourfolds of decrease per $50 \mu \mathrm{g} / \mathrm{ml}$ of increase in PbLE concentration. Because biofilm resistance depends on aggregation of bacteria in multicellular communities, one strategy might be to develop therapies that disrupt the multicellular structure of the biofilm. If the multi-cellularity of the biofilm is defeated, the host defences might be able to resolve the infection, and the efficacy of antibiotics might be restored. Potential therapies include enzymes that dissolve the matrix polymers of the biofilm, chemical reactions that block biofilm matrix synthesis, and analogues of microbial signalling molecules that interfere with cell-to-cell communication, required for normal biofilm formation (Stewart and Costerton 2001).

This study lays a foundation that a simultaneous administration of PbLE along with antibiotics (reported to be resistant to $P$. aeruginosa) may help in bringing back the sensitivity to effect in antibiotic therapy.

Pyocyanin contributes to the persistence of $P$. aeruginosa infection by causing detrimental effects toward lung (Lyczak et al. 2002) epithelial cells and by deregulating inflammatory response initiated by the host. Pyocyanin 
Fig. 1 Effect of piper betle ethanolic leaf extract (PbLE) on the mobility pattern of Pseudomonas aeruginosa PAO1. a Effect of swarming activity, b swimming activity and $\mathbf{c}$ twitching activity of Pseudomonas aeruginosa PAO1 with increasing concentrations $(25,50,75$ and $100 \mu \mathrm{g} / \mathrm{ml})$ of PbLE (inset showing the colony morphology of the bacteria)

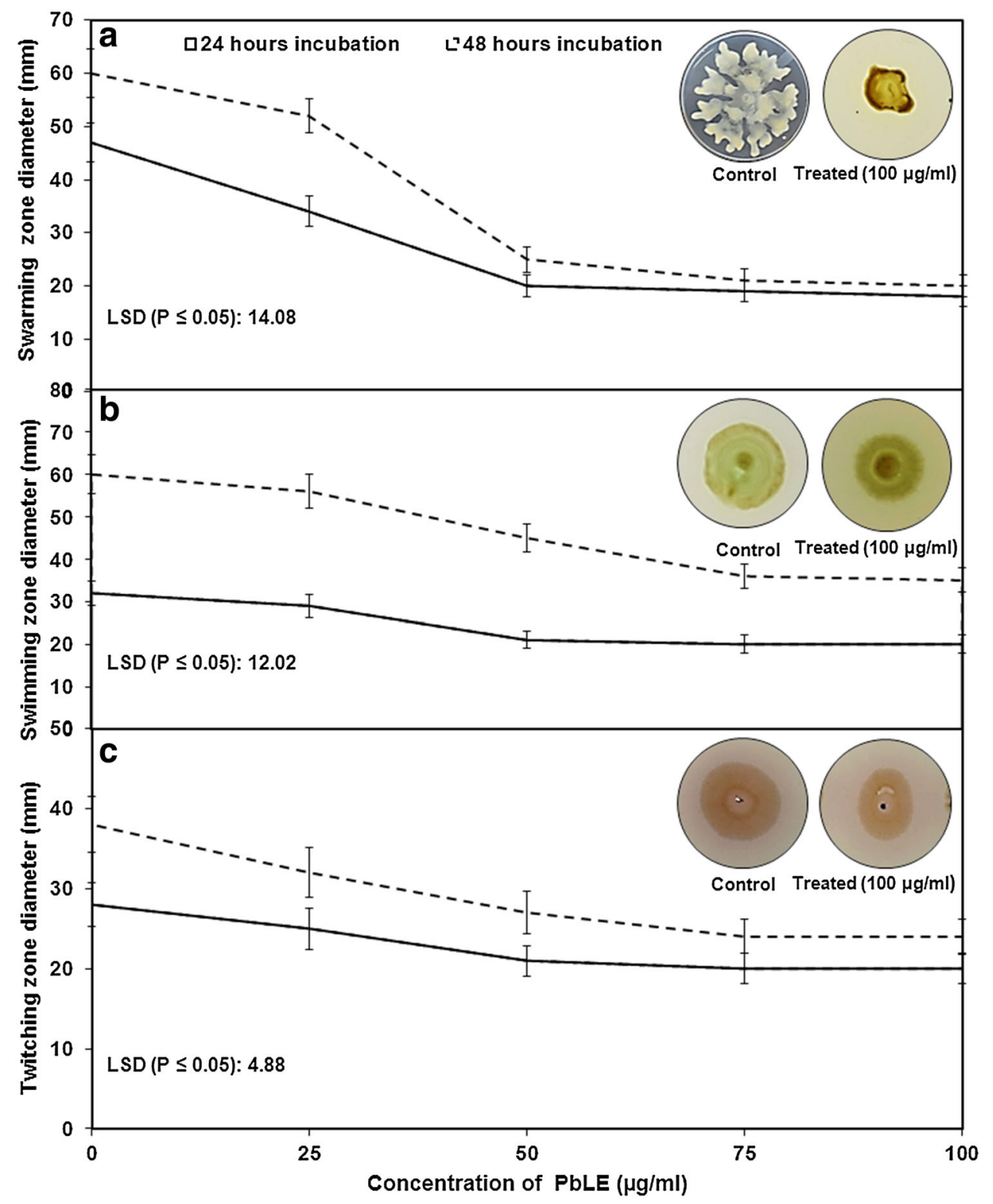

synthesis is regulated by a complex synchrony of lasR-lasI, rhlR-rhlI and mvfR-haq QS-system whereby mutations in these systems lead to the deficiency of pyocyanin synthesis (Priya et al. 2013).

Our studies depict Pyocyanin production to be having a steady decrease with increasing concentrations of PbLE i.e. beyond $150 \mu \mathrm{g} / \mathrm{ml}$ the rate of decrease comes to a constant (Fig. 2).

From our studies and available literature, it could be postulated that the PbLE may have inhibited the QS-systems at its gene expression level or acts as an antagonist to decrease pyocyanin production.
Comparing the above observations (Fig. 3) with the growth curve of $P$. aeruginosa PAO1 in presence different concentrations of PbLE; it does not show any variation or decrease in the growth pattern as compared to PbLE free medium. Thus, it makes it evident that PbLE irrespective of its concentration has no effect on the cell division of $P$. aeruginosa PAO1 but the biofilm assay and pyocyanin production does indicate that PbLE has a marked effect on the anabolism of biofilm and pyocyanin production. Hence, this effect also has an effect on the QS abilities of the bacteria in presence of PbLE. This indicates on the possible reducing virulence of $P$. aeruginosa. 


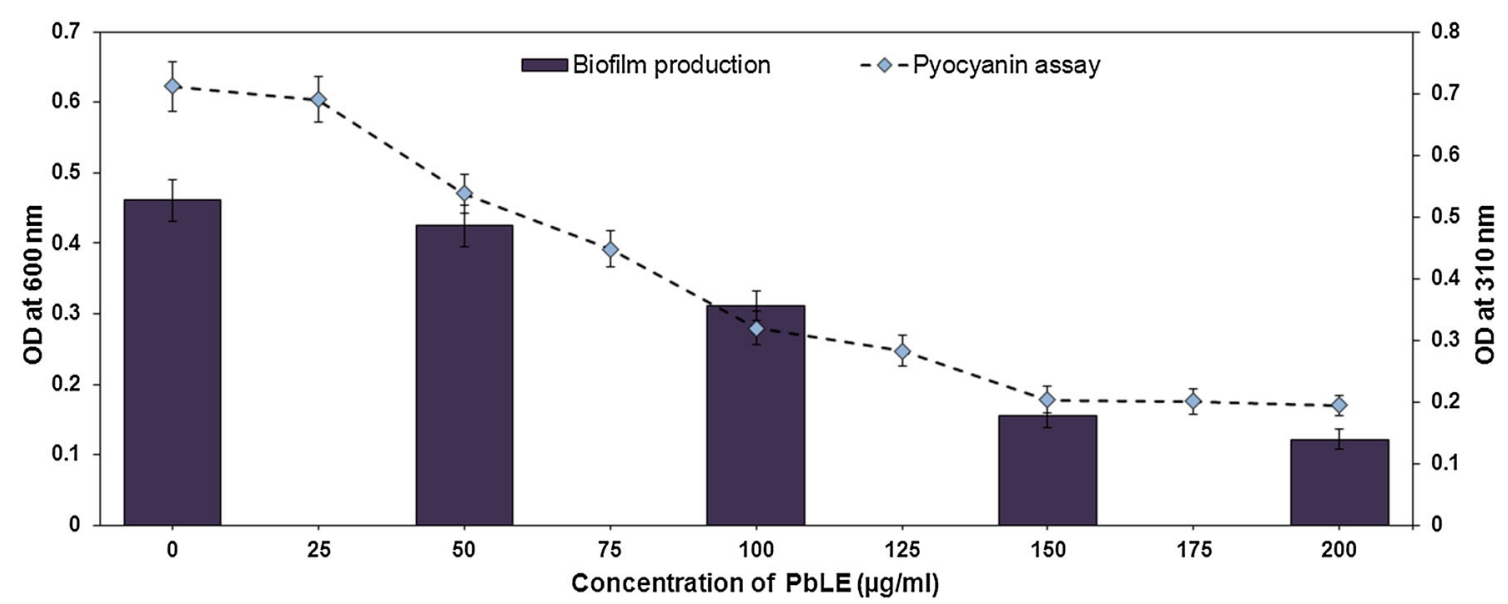

Fig. 2 Inhibition of Pseudomonas aeruginosa PAO1 biofilm and pyocyanin production in presence of different concentrations of PbLE. Bar chart represents the mean results from triplet cultures of three independent experiments, with error bar representing standard deviation

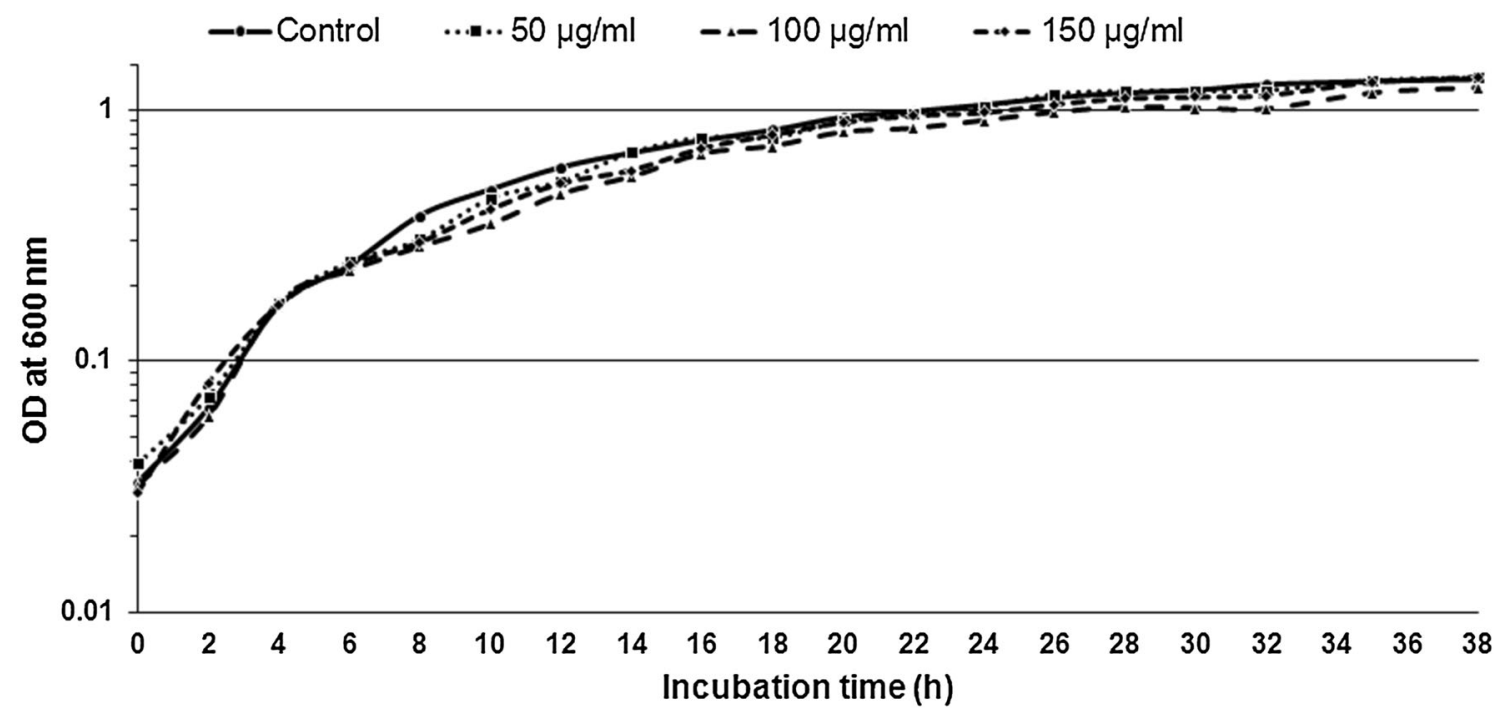

Fig. 3 Growth curve patterns of Pseudomonas aeruginosa PAO1 in presence of different concentrations of PbLE (0, 50, 100 and 150 $\mu \mathrm{g} / \mathrm{ml})$

\section{Conclusion}

Based on the results obtained from this study, it is proven that the ethanolic extract of $P$. betle demonstrates anti-QS capabilities. It may have also been able to attenuate QSregulated virulence determinants of $P$. aeruginosa PAO1. Newer insights may be provided by the bioactive compounds in the extract leading towards discovering potential antipathogenic drugs to combat emerging multidrug resistant pathogens. Future work should direct to the isolation and characterization of active molecule that is responsible for the anti-QS properties of the ethanolic extract of $P$. betle leaf.

Acknowledgments This work is supported in part by Science and Engineering Research Board (Grant No. SR/FT/LS-102/2010), Government of India.
Conflict of interest The authors declare that they have no conflict of interest in the publication.

Open Access This article is distributed under the terms of the Creative Commons Attribution 4.0 International License (http:// creativecommons.org/licenses/by/4.0/), which permits unrestricted use, distribution, and reproduction in any medium, provided you give appropriate credit to the original author(s) and the source, provide a link to the Creative Commons license, and indicate if changes were made.

\section{References}

Adonizio A, Kong KF, Mathee K (2008) Inhibition of quorum sensing-controlled virulence factor production in Pseudomonas aeruginosa by South Florida plant extracts. Antimicrob Agents Chemother 52:198-203 
Chong YM, Yin WF, Ho CY, Mustafa MR, Hadi AHA, Awang K, Narrima P, Koh CL, Appleton DR, Chan KG (2011) Malabaricone C from Myristica cinnamomea exhibits anti-quorum sensing activity. J Nat Prod 74:2261-2264

Choo JH, Rukayadi Y, Hwang JK (2006) Inhibition of bacterial quorum sensing by vanilla extract. Lett Appl Microbiol 42:637-641

Friedstat JS, Moore ME, Weber JM, Fagan SP, Goverman J (2013) Selection of appropriate empiric gram-negative coverage in a multinational pediatric burn hospital. J Burn Care Res 34:203-210

Fuqua C, Greenberg EP (2002) Listening in on bacteria: acylhomoserine lactone signalling. Nat Rev Mol Cell Biol 3:685-695

Girard G, Bloemberg GV (2008) Central role of quorum sensing in regulating the production of pathogenicity factors in Pseudomonas aeruginosa. Future Microbiol 3:97-106

Govan JR, Deretic V (1996) Microbiol pathogenesis in cystic fibrosis: mucoid Pseudomonas aeruginosa and Burkholderia cepacia. Microbiol Rev 60:539-574

Guha P (2006) Betel leaf: the neglected green gold of India. J Hum Ecol 19:87-93

Inoue T, Shingaki R, Fukui K (2008) Inhibition of swarming motility of Pseudomonas aeruginosa by branched-chain fatty acids. FEMS Microbiol Lett 281:81-86

Jimenez PN, Koch G, Thompson JA, Xavier KB, Cool RH, Quax WJ (2012) The multiple signaling systems regulating virulence in Pseudomonas aeruginosa. Microbiol Mol Biol Rev 76:46-65

Krishnann T, Yin WF, Chan KG (2012) Inhibition of quorum sensingcontrolled virulence factor production in Pseudomonas aeruginosa PAO1 by ayurveda spice clove (Syzygium aromaticum) bud extract. Sensors 12:4016-4030

Kumar L, Chhibber S, Kumar R, Kumar M, Harjai K (2015) Zingerone silences quorum sensing and attenuates virulence of Pseudomonas aeruginosa. Fitoterapia 102:84-95

Lanini S, D'Arezzo S, Puro V, Martini L, Imperi F, Piselli P, Montanaro M, Paoletti S, Visca P, Ippolito G (2011) Molecular epidemiology of a Pseudomonas aeruginosa hospital outbreak driven by a contaminated disinfectant-soap dispenser. PLoS ONE. doi:10.1371/journal.pone.0017064

Lyczak JB, Cannon CL, Pier GB (2002) Lung infections associated with cystic fibrosis. Clin Microbiol Rev 15:194-222

Maity TR, Samanta A, Jana D, Saha B, Datta S (2014) Effect of Piper betle leaf extract on post-harvest physiology and vascular blockage in relation to vase life and keeping quality of cut spike of tuberose (Polianthes tuberosa L. cv. single). Ind J Plant Physiol 19:250-256

Mukherjee PK, Wahile A (2006) Integrated approaches towards drug development from ayurveda and other Indian system of medicines. J Ethnopharmacol 103:25-35

Nair R, Chanda S (2008) Antimicrobial activity of Terminalia catappa, Manilkara zapota, and Piper betle leaf. Indian J Pharm Sci 70:390-393

Packiavathy IASV, Priya S, Pandian SK, Ravi AV (2014) Inhibition of biofilm development of uropathogens by curcumin - an antiquorum sensing agent from Curcuma longa. Food Chem 148:453-460

Priya K, Yin WF, Chan KG (2013) Anti-quorum sensing activity of the traditional Chinese herb, Phyllanthus amarus. Sensors 13:14558-14569

Siddiqui MF, Sakinah M, Ismail AF, Matsuura T, Zularisam AW (2012) The anti-biofouling effect of Piper betle extract against Pseudomonas aeruginosa and bacterial consortium. Desalination 288:24-30

Smith DJ, Lamont IL, Anderson GJ, Reid DW (2013) Targeting iron uptake to control Pseudomonas aeruginosa infections in cystic fibrosis. Eur Respir J 42:1723-1736

Stewart PS, Costerton JW (2001) Antibiotic resistance of bacteria in biofilms. Lancet 358:135-138

Tan LY, Yin WF, Chan KG (2013) Piper nigrum, Piper betle and Gnetum gnemon-natural food sources with anti-quorum sensing properties. Sensors 13:3975-3985

Tron EAM, Wilke HL, Petermann SR, Rust L (2004) Pseudomonas aeruginosa from canine otitis externa exhibit a quorum sensing deficiency. Vet Microbiol 99:121-129

Vattem DA, Mihalik K, Crixell SH, McLean RJC (2007) Dietary phytochemicals as quorum sensing inhibitors. Fitoterapia 78:302-310

Whitehead NA, Barnard AM, Slater H, Simpson NJ, Salmond GP (2001) Quorum sensing in gram-negative bacteria. FEMS Microbiol Rev 25:365-404

Zhu H, Bandara R, Conibear TCR, Thuruthyil SJ, Rice SA, Kjelleberg S (2004) Pseudomonas aeruginosa with LasI quorum-sensing deficiency during corneal infection. Invest Ophthalmol Vis Sci 45:1897-1903 